\title{
Risk of firearm injuries among children and youth of immigrant families
}

\author{
Natasha R. Saunders MSc MD, Hannah Lee, Alison Macpherson PhD, Jun Guan MSc, Astrid Guttmann MSc MDCM
}

Cite as: CMAJ 2017 March 27;189:E452-8. doi: 10.1503/cmaj.160850

CMAJ Podcasts: author interview at https://soundcloud.com/cmajpodcasts/160850-res

Visual abstract available at www.cmaj.ca/lookup/suppl/doi:10.1503/cmaj.160850/-/DC2

\begin{abstract}
BACKGROUND: Firearm injuries contribute to substantial morbidity and mortality. The immigrant paradox suggests that, despite being more socially disadvantaged, immigrants are less likely than nonimmigrants to have poor outcomes. We tested the association of immigrant characteristics with firearm injuries among children and youth.
\end{abstract}

METHODS: We conducted a populationbased cohort study involving residents of Ontario aged 24 years and younger from 2008-2012 using health and administrative databases. We estimated rate ratios of unintentional and assault-related firearm injuries by immigrant status using Poisson regression models with Generalized Estimating Equations.
RESULTS: We included 15866954 nonimmigrant and 4551291 immigrant personyears in our analysis. Nonimmigrant males had 1032 unintentional (12.4 per $100000,95 \%$ confidence interval [Cl] 11.7-13.2) and 304 assault-related (3.6 per $100000,95 \% \mathrm{Cl} 3.2-4.0$ ) firearm injuries. Immigrant males had 148 unintentional (7.2 per $100000,95 \% \mathrm{Cl} 6.1-8.5)$ and 113 assault-related (5.5 per 100000 , $95 \% \mathrm{Cl} 4.5-6.6)$ firearm injuries. Compared with nonimmigrants, immigrants had a lower rate of unintentional firearm injury (adjusted rate ratio $0.5,95 \% \mathrm{Cl}$ 0.4-0.6) but a similar rate of assaultrelated firearm injury. Among immigrants, refugees had a $43 \%$ higher risk of assault-related firearm injury compared with nonrefugees (adjusted rate ratio 1.4, 95\% Cl 1.0-2.0). Immigrants from Central America and Africa accounted for $68 \%$ of immigrants with assaultrelated firearm injuries.

INTERPRETATION: Compared with nonimmigrants, immigrant children and youth had a lower risk of unintentional firearm injury, although the risk of assault-related firearm injury was higher among refugees and immigrants from Central America and Africa. The results suggest that prevention strategies for firearm safety should target nonimmigrant youth as well as these newly identified high-risk immigrant populations.
$\mathbf{F}$ irearm injuries are a substantial cause of morbidity and mortality among children and youth. ${ }^{1,2}$ They have a high

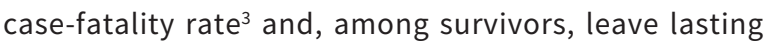
repercussions with associated high direct medical and indirect costs. ${ }^{4}$ In Canada, an average of 1300 firearm-related deaths occur annually ${ }^{5}$ and many more firearm injuries lead to hospital admissions or emergency department visits., ${ }^{1,6,7}$ Several risk factors have been identified for sustaining a firearm injury or being a victim of a homicide. They include young age $(<5 \mathrm{yr})$ and late adolescence, male sex, low socioeconomic status, Indigenous ethnicity, black race, access to a firearm in the home and involvement in a gang. ${ }^{1,8-12}$ Canadian emergency physicians and pediatricians have recognized the need to identify at-risk populations to enable targeted strategies to prevent violent injuries. ${ }^{6,9}$ Such strategies are essential to counter the rising trend of violent crimes involving handguns in major Canadian cities ${ }^{12}$ and to lessen the burden of preventable unintentional firearm injuries.
One potential at-risk group includes the growing population of immigrant children and youth in Canada. Immigrants now make up $19 \%$ of the Canadian population. ${ }^{13}$ Although studies have reported lower rates of unintentional injury among immigrants than among Canadian-born children and youth, ${ }^{14,15}$ there was cause-specific variability and no population-based data on assaults were included. The immigrant paradox ${ }^{16}-$ a theory that, despite facing social disadvantage, new immigrants have better health outcomes than native-born people - has not been consistently observed among children ${ }^{17}$ nor well studied among victims of violent crime or unintentional firearm injuries. It is unknown whether immigration itself or immigration-related factors such as time since migration, region of origin and refugee status are related to firearm injury. Immigrants may bring their home country's normative behaviours with them, including perceived need for firearm ownership. ${ }^{18}$ Firearm ownership varies across the globe, with rates as high as 112 firearms per 100 people in the 
United States, in contrast to 0.6 firearms per 100 in Japan ${ }^{2}$ and 26 per 100 in Canada. ${ }^{5}$ Global cultural norms for use of firearms for self-protection and involvement with gangs also vary. Moreover, circumstances that lead to migration, settlement supports and integration may affect the risk of firearm injuries.

As Canada embraces more immigrants, in particular from areas with civil unrest and economic hardship ${ }^{19}$ in the context of an increasing spate of firearm injuries, ${ }^{5,20}$ delineation of firearm risk among immigrants is important. We conducted a study to describe the epidemiology of victims of unintentional and assault-related firearm injuries among immigrant children and youth in Ontario and to test the association of immigration characteristics with firearm injuries.

\section{Methods}

We conducted a population-based cohort study using health and other administrative databases available at the Institute for Clinical Evaluative Sciences (ICES).

\section{Data sources}

Ontario has a single-payer universal Ontario Health Insurance Plan (OHIP) through which most hospital and physician services are insured. Unique OHIP identification numbers were encoded and linked to data from several health and administrative databases. The Registered Persons Database, Ontario's health care registry, contains sociodemographic information, including age, sex and postal code, of all OHIP-eligible residents. The Canadian Institute for Health Information's Discharge Abstract Database and National Ambulatory Care Reporting System collect data on hospital admissions and emergency department visits, respectively. The Ontario Registrar General - Death Files includes all deaths by cause. The Rurality Index of Ontario was used to determine rurality. ${ }^{21}$ Statistics Canada's Postal Code Conversion File was used to determine neighbourhood income quintiles at the dissemination area level using Canadian census data (2006). The 2006 census, used also for population denominators, was chosen because the 2011 census was completed voluntarily and may introduce bias. Data from the most recent census (2016) are not yet available.

Immigration information was obtained from Immigration, Refugees and Citizenship Canada's Permanent Resident Database. Permanent residents (immigrants granted permission to live and work in Canada without limitations on their stay) are eligible for provincially insured health care services, typically within 3 months after arrival. The available portion of this database includes data for all permanent residents to Canada landing in Ontario from 1985 to 2012, including those who eventually become citizens, but not including undocumented or temporary residents (e.g., foreign students). Probabilistic linkage to the Registered Persons Database identifies about $86 \%$ of permanent resident immigrants, and data quality and linkage details have been published elsewhere..$^{22,23}$ The MOMBABY Database at ICES links inpatient admission records from the Discharge Abstract Database for mothers and their newborns delivered in Ontario hospitals. ${ }^{22}$ This database was used to identify newborns born in Canada to immigrant mothers.

\section{Study population}

We included all children and youth aged 24 years and younger living in Ontario from Jan. 1, 2008, to Dec. 31, 2012, who had a valid OHIP number. Individuals with a missing or invalid OHIP number or non-Ontario residents were excluded. Within the study period, we created 5 annual cohorts and assigned sociodemographic data annually with prespecified cut points based on data available as of Dec. 31 of the cohort year.

\section{Outcome measures}

The primary outcome measures were unintentional and assaultrelated firearm injuries. Injuries were defined in terms of emergency department visits, hospital admissions, and in- and out-of-hospital deaths using International Statistical Classification of Diseases and Related Health Problems, 10th Revision, Clinical Modification (ICD10-CM) codes for external causes of injury (Appendix 1, available at www.cmaj.ca/lookup/suppl/doi:10.1503/cmaj.160850/-/DC1). ${ }^{24}$ Firearm injuries identified with the ICD-9-CM codes were validated in a study that used state-level administrative data in Washington (sensitivity $92 \%$ and positive predictive value $94 \%$ ). ${ }^{25}$ Firearm injury intent from computerized discharge records and expert chart abstraction has shown $83 \%$ agreement. ${ }^{25}$ Intent is determined from internationally agreed upon codes used by the World Health Organization. ${ }^{26}$ We included multiple injury events for the same patient if the injury did not result from the same episode.

\section{Predictor}

The main predictor was immigrant status, defined as any child or youth with permanent residency status or born to a mother with permanent residency status, landing in Canada after Jan. 1, 1985. Children born to immigrant mothers before 1985, when immigration data became available, were categorized as nonimmigrants. Children of immigrant mothers were included because risk of injury is associated with maternal immigrant status, ${ }^{27}$ and maternal immigrant status may reflect a child or youth's exposure to firearms and firearm-related behaviours in the home environment.

\section{Covariates}

Male sex, older adolescence and low socioeconomic status have been associated with firearm injury or homicide risk. ${ }^{1,9,28}$ Therefore, we included age, sex and neighbourhood income quintile as covariates, as well as rurality of residence. Immigration characteristics used included visa class (refugee v. nonrefugee immigrant), region of origin (based on country of birth using modified Immigration, Refugees and Citizenship Canada world regions (Appendix 2, available at www.cmaj.ca/lookup/suppl/doi:10.1503/ cmaj.160850/-/DC1) ${ }^{13}$ and time since migration to Canada (recent: 0-5 yr, intermediate: 6-10 yr, long term: > $10 \mathrm{yr}$ ).

\section{Statistical analysis}

We calculated the total number of firearm injuries during the 5 study years and age-sex standardized rates per 100000 population using 2006 census estimates. We followed the strict privacy guidelines set out by ICES for use of health administrative data for health research without individual consent. Institutional policy requires suppression of cell sizes of less than 6 to ensure noniden- 
tification. We calculated rate ratios with 95\% confidence intervals (Cls) of unintentional and assault-related firearm injuries by immigrant status using multivariable Poisson regression models with Generalized Estimating Equations to account for clustering of multiple injury events within victims. Separate regression models were built for each immigration characteristic. All models were adjusted for age, sex, neighbourhood income quintile and rurality. Results are presented as the sum of the 5 annual cohorts, ageand sex-standardized rates, and rate ratios.

We conducted sensitivity analyses in which we excluded children born in Ontario to immigrant mothers and children living in rural areas.

We performed all statistical modelling using SAS Enterprise Guide, version 6.1 (SAS Institute).

\section{Ethics approval}

Research ethics board approval was obtained from Sunnybrook Health Sciences Centre and The Hospital for Children, Toronto, Ontario.

\section{Results}

We included almost 16 million nonimmigrant and 4.5 million immigrant person-years in our analyses (Table 1 ). Immigrants were younger and had larger proportions living in lower income neighbourhoods. Among the immigrants, most (98.8\%) lived in urban areas, $15.6 \%$ were refugees, and $24.2 \%$ had recently immigrated. Almost half (49.0\%) were from South and East Asia.

In the 5-year study period, male nonimmigrants had 1032 unintentional (12.4 per $100000,95 \% \mathrm{Cl} 11.7-13.2$ ) and 304 assault-related (3.6 injuries per $100000,95 \% \mathrm{Cl} 3.2-4.0$ ) firearm injuries. In contrast, male immigrants had 148 unintentional (7.2 per $100000,95 \% \mathrm{Cl} 6.1-8.5)$ and 113 assault-related (5.5 per $100000,95 \% \mathrm{Cl} 4.5-6.6)$ firearm injuries. Female nonimmigrants had 137 unintentional ( 1.7 per $100000,95 \% \mathrm{Cl} 1.4-2.0)$ and 31 assault-related $(0.4$ per $100000,95 \% \mathrm{Cl} 0.3-0.5)$ firearm injuries. Female immigrants had 12 unintentional and less than 6 assaultrelated firearm injuries (Table 2 ). Most (68\%) of the assaultrelated injuries and a large proportion (43\%) of unintentional firearm injuries were in immigrants from Africa and Central America (Table 2).

The risk of unintentional firearm injury was lower among immigrant children and youth (adjusted rate ratio $0.5,95 \% \mathrm{Cl}$ 0.4-0.6), whereas the risk of assault-related firearm injury was not associated with immigrant status (Table 3). The results of the sensitivity analysis excluding children born in Canada to immigrant mothers and children living in rural areas did not change the direction of these associations. Predictors of firearm injuries included older age (15-24 yr), male sex and low income quintile. The strength of these associations was greater with assaultrelated than with unintentional firearm injuries, as well as within the immigrant group compared with the nonimmigrant group in the stratified models. Rural residence was predictive of unintentional firearm injury, and urban residence was positively associated with risk of assault from a firearm.
Figure 1 shows the adjusted rate ratios for firearm injury by immigration characteristics. Compared with nonimmigrants, refugees had a $43 \%$ higher risk of an assault-related firearm injury (adjusted rate ratio $1.4,95 \% \mathrm{Cl} 1.0-2.0$ ) but they did not differ in risk of unintentional firearm injury. Nonrefugee immigrants had a $55 \%$ lower risk of unintentional firearm injury compared with nonimmigrants. With increasing duration of residence in Canada, risk of both unintentional and assault-related firearm injuries increased. The risk of unintentional firearm injury was lower

Table 1: Characteristics of immigrant and nonimmigrant children and youth in Ontario, 2008-2012

Group; no. (\%) in person-years

\begin{tabular}{|ccc|}
\hline Characteristic & Nonimmigrants & Immigrants \\
\hline $\begin{array}{l}\text { Overall } \\
\text { Age group, yr }\end{array}$ & 15866954 & 4551291 \\
\hline 15 & $8653435(54.6)$ & $2810882(61.8)$ \\
\hline $15-24$ & $7213519(45.5)$ & $1740409(38.2)$ \\
\hline Sex & & \\
\hline Female & $7742179(48.8)$ & $2216374(48.7)$ \\
\hline Male & $8124775(51.2)$ & $2334917(51.3)$ \\
\hline
\end{tabular}

Neighbourhood income quintile

\begin{tabular}{|c|c|c|}
\hline 1 (lowest) & $2828574(17.8)$ & $1336597(29.4)$ \\
\hline 2 & 2863597 (18.0) & $992300(21.8)$ \\
\hline 3 & 3129947 (19.7) & 912593 (20.1) \\
\hline 4 & $3486411(22.0)$ & 794804 (17.5) \\
\hline 5 (highest) & 3558425 (22.4) & 514997 (11.3) \\
\hline \multicolumn{3}{|l|}{ Rurality } \\
\hline Urban & $13670442(86.2)$ & 4496519 (98.8) \\
\hline Rural & $2196512(13.8)$ & $54772(1.2)$ \\
\hline \multicolumn{3}{|l|}{ Immigrant class } \\
\hline Nonrefugee & - & $3842758(84.4)$ \\
\hline Refugee & - & $708533(15.6)$ \\
\hline \multicolumn{3}{|l|}{ Duration of residence } \\
\hline Recent & - & $1102744(24.2)$ \\
\hline Intermediate & - & $1214801(26.7)$ \\
\hline Long term & - & 2233746 (49.1) \\
\hline \multicolumn{3}{|l|}{ Region of origin } \\
\hline US/UK/Western Europe & - & $519096(11.4)$ \\
\hline East Asia and Pacific & - & $1017151(22.3)$ \\
\hline South Asia & - & $1213166(26.7)$ \\
\hline $\begin{array}{l}\text { Eastern Europe/Central } \\
\text { Asia }\end{array}$ & - & $357773(7.9)$ \\
\hline Africa & - & $402717(8.8)$ \\
\hline Middle East & - & 428455 (9.4) \\
\hline South America & - & $222902(4.9)$ \\
\hline Central America & - & $388443(8.5)$ \\
\hline Unknown & - & $1588(0.03)$ \\
\hline
\end{tabular}


among immigrants than among nonimmigrants regardless of duration of residence. The risk of assault-related firearm injury was 1.3 times higher among long-term immigrants (in Canada longer than $10 \mathrm{yr}$ ) compared with nonimmigrants (adjusted rate ratio $1.35,95 \% \mathrm{Cl} 1.10-1.66$ ), and it was higher among immigrants from Africa and Central America (Africa: adjusted rate ratio 2.8, 95\% Cl 2.0-4.1; Central America: adjusted rate ratio 4.1, 95\% Cl 3.0-5.6).

\section{Interpretation}

Results from this large, population-based study suggest that immigration is protective and mitigates the risk of unintentional firearm injuries but increases the risk of a firearm assault in certain subgroups. Among immigrants, refugees were at particularly high risk of firearm injuries regardless of intent, as were immigrants with a longer duration of residence in Canada. There was

Table 2: Frequency and age- and sex-standardized rates of firearm injury by immigration status and sociodemographic characteristics, 2008-2012

Unintentional injuries

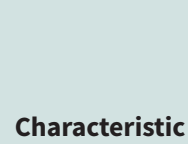

Age group, yr (sex standardized)

$$
<15
$$

15-24

Sex (age standardized)

Female

Neighbourhood income quintile

$$
1 \text { (lowest) }
$$

$$
2
$$

3

4

5 (highest)

Rurality

Urban

Rural

Immigrant class

Nonrefugee

Refugee

Duration of residence

Recent

Intermediate

Long term

Region of origin

US/UK/Western Europe

East Asia and Pacific

South Asia

Eastern Europe/Central Asia

Africa

Middle East

South America

Central America

Nonimmigrants

Rate per

No. $\quad 100000(95 \% \mathrm{CI})$
292

877

$3.4(3.0-3.8)$

$12.1(11.4-13.0)$

20

140

137

1032

$1.7(1.5-2.1)$

$12.4(11.7-13.2$

12

148

354

228

$12.2(10.9-13.5)$

$7.7(6.7-8.7)$

$7.7(6.8-8.8)$

$5.5(4.7-6.3)$

$4.0(3.4-4.7)$

$6.3(5.9-6.7) \quad 160^{*}$

889

280

$12.5(11.0-14.0) \leq 5$

Immigrants

Rate per No. $100000(95 \% \mathrm{CI})$

No.

$000(95 \% \mathrm{CI})$ Rate per $100000(95 \% \mathrm{CI})$

$$
0.7(0.4-1.1)
$$

$8.1(6.8-9.5)$

$0.6(0.3-1.0)$

$7.2(6.1-8.5)$

$6.0(4.7-7.6)$

$4.0(2.8-5.6)$

$3.1(2.0-4.5)$

2.5 (1.5-4.1)

$2.7(1.4-4.6)$

$3.9(3.3-4.6)$

$3.4(2.8-4.1)$

49

$6.4(4.7-8.4)$

$1.7(1.0-2.8)$

$4.2(3.0-5.7)$

$4.9(4.0-5.9)$

$4.4(2.8-6.7)$

$1.4(0.8-2.4)$

$2.1(1.3-3.2)$

$3.8(2.0-6.6)$

11.5 (8.1-15.8)

$3.3(1.8-5.6)$

$3.4(1.4-6.9)$

9.5 (6.5-13.4)

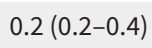

31

304

$0.4(0.3-0.5)$

$3.6(3.2-4.0)$

$\leq 5$

$113^{*}$

$5.5(4.5-6.6)$

4.9 (4.2-5.8)

58

$5.0(3.8-6.5)$

$2.5(2.0-3.1)$

33

$1.6(1.2-2.1)$

14

$3.8(2.6-5.3)$

0.9 (0.6-1.3)

$8 *$

$1.8(1.0-2.9)$

$0.7(0.4-1.0)$

2.1 (1.9 2.4)

113

$2.9(2.4-3.5)$

28

$1.2(0.8-1.8)$

0

$2.4(1.9-3.0)$

$4.7(3.3-6.5)$

14

$1.5(0.8-2.6)$

24

75

2.5 (1.6-3.8)

$3.6(2.8-4.5)$

10

$2.1(1.0-3.9)$

$\leq 5$

9

$1.0(0.5-2.0)$

$\leq 5$

32

$9.8(6.7-13.9)$

$\leq 5$

$\leq 5$

45

${ }^{\star}$ Number rounded to avoid back-calculation of small cells $(\leq 5)$. 
wide variation in the risk of firearm injury by region of origin, with considerably high rates among immigrants from Africa and Central America.

Canada has relatively few firearm injuries, although many countries, predominantly in South and East Asia, have even lower rates than observed in the current study. ${ }^{29}$ Nonetheless, rates of unintentional firearm injury among nonimmigrant Canadian children and youth are concerning and warrant further attention. The predictors of firearm injury in our study were comparable to those in other studies that reported males, low socioeconomic status, and late adolescence and young adulthood were associated with firearm injury. ${ }^{1,9,28}$ Low rates of unintentional firearm injury among immigrants, despite a relatively large proportion living in low-income neighbourhoods, supports the immigrant paradox. Few studies have evaluated the association between immigration and risk of firearm injuries. A Swedish population-based study reported that foreign-born adults did not differ from native-born Swedes in the odds of nonfatal unintentional firearm injuries but were at higher risk of being a victim of attempted murder with a firearm. ${ }^{30} \mathrm{Simi}-$ larly, homicides were 40\% lower among Italians than among immigrant males in Italy, although firearm-specific rates were not reported. ${ }^{31}$ In California, foreign-born people were overrepresented in homicides of people 15 to 34 years old. ${ }^{32}$ Immigration-specific factors such as visa class and duration of residence and their relation to firearm injuries were not explored in these studies.
Possible contributing factors to the increased risk of assaultrelated firearm injuries in immigrant subgroups may relate to higher rates of poverty, lack of access to resources, and more bullying and peer aggression among first-generation immigrant adolescents. ${ }^{33}$ The finding that, overall, immigration was not associated with assault-related firearm injuries is consistent with the finding of Chavez and colleagues, ${ }^{34}$ who reported no association of neighbourhood-level immigration with changes in homicide rates. In our study, the observed variation in firearm injury by region of origin may have been related to higher participation in Canadian gangs by Indo-Asian, Caribbean and African immigrants than by those from other regions, and it highlights the need to ensure a healthy transition to Canada for these particular at-risk groups. ${ }^{35}$

Household gun ownership increases the risk of unintentional firearm injuries. ${ }^{36}$ The lower rates of unintentional firearm injuries observed among nonrefugee immigrants may relate to low rates of firearm ownership by immigrants, residence in urban areas and selection policies for immigrants to Canada who are highly educated. ${ }^{13,37}$ The increasing risk of firearm injury with longer time spent in Canada highlights one area for possible public health education and consumer regulation around gun safety and storage. It also brings to light a need to improve longer-term settlement and integration services for immigrants to maintain healthy behaviours with increasing duration of residence in Canada.

Table 3: Adjusted rate ratios of unintentional and assault-related firearm injuries by immigrant status and sociodemographic characteristics

\begin{tabular}{|c|c|c|c|c|c|c|}
\hline \multirow[b]{2}{*}{ Variable } & \multicolumn{3}{|c|}{$\begin{array}{c}\text { Unintentional injuries; } \\
\text { adjusted rate ratio* }(95 \% \mathrm{Cl})\end{array}$} & \multicolumn{3}{|c|}{$\begin{array}{l}\text { Assault-related injuries; } \\
\text { adjusted rate ratio* }(95 \% \mathrm{Cl})\end{array}$} \\
\hline & All & Nonimmigrants & Immigrants & All & Nonimmigrants & Immigrants \\
\hline \multicolumn{7}{|l|}{ Overall } \\
\hline Nonimmigrant (ref) & 1.0 & - & - & 1.0 & - & - \\
\hline Immigrant & $0.5(0.4-0.6)$ & - & - & $1.0(0.8-1.30)$ & - & - \\
\hline \multicolumn{7}{|l|}{ Age group, yr } \\
\hline$<15$ (ref) & 1.0 & - & - & 1.0 & - & - \\
\hline $15-24$ & $4.0(3.5-4.6)$ & $3.6(3.1-4.1)$ & $11.3(6.7-18.8)$ & $22.7(15.0-34.3)$ & $17.5(11.2-27.3)$ & $59.3(18.8-187.3)$ \\
\hline \multicolumn{7}{|l|}{ Sex } \\
\hline Female (ref) & 1.0 & - & - & 1.0 & - & - \\
\hline Male & $7.5(6.3-9.1)$ & $7.2(5.9-8.7)$ & $11.9(6.3-22.4)$ & $12.1(8.4-17.5)$ & $9.5(6.4-13.9)$ & $53.2(13.1-215.6)$ \\
\hline \multicolumn{7}{|c|}{ Neighbourhood income quintile } \\
\hline 1 (lowest) & $2.9(2.3-3.5)$ & $2.9(2.4-3.6)$ & $2.1(1.1-3.9)$ & $7.8(5.1-11.9)$ & $7.4(4.8-11.4)$ & $23.4(3.2-169.7)$ \\
\hline 2 & $1.8(1.5-2.3)$ & $1.9(1.5-2.3)$ & $1.4(0.7-2.9)$ & $4.4(2.8-6.8)$ & $3.7(2.3-5.9)$ & $17.9(2.4-130.9)$ \\
\hline 3 & $1.8(1.5-2.2)$ & $1.9(1.5-2.3)$ & $1.1(0.5-2.2)$ & $2.5(1.6-4.0)$ & $2.3(1.4-3.7)$ & $8.1(1.0-62.8)$ \\
\hline 4 & $1.3(1.0-1.6)$ & $1.3(1.1-1.7)$ & $0.9(0.4-1.9)$ & $1.4(0.9-2.4)$ & $1.3(0.8-2.3)$ & $4.8(0.6-38.7)$ \\
\hline 5 (highest) (ref) & 1.0 & - & - & 1.0 & - & - \\
\hline \multicolumn{7}{|l|}{ Rurality } \\
\hline Rural (ref) & 1.0 & - & - & 1.0 & - & - \\
\hline Urban & $0.5(0.5-0.6)$ & $0.5(0.5-0.6)$ & $0.3(0.1-1.3)$ & $2.0(1.3-2.9)$ & $1.9(1.3-2.9)$ & - \\
\hline
\end{tabular}


Although the observed rates of firearm injuries in our study were substantially lower than those in many other countries, ${ }^{1,2}$ they nonetheless represent injuries that are often catastrophic and entirely preventable. A number of interventions have been associated with reductions in firearm injury rates, including firearm legislation restricting gun ownership, registration and access, ${ }^{38,39}$ and recommendations around safe firearm storage. ${ }^{40}$ For reducing assault-related firearm injuries specifically, neighbourhood-level community engagement strategies, ${ }^{41}$ conflict resolution programs, ${ }^{42}$ emergency department and hospital interventions with brief motivational interviewing and cognitive skills training, ${ }^{43}$ and community-based programs to develop social skills ${ }^{44}$ have shown promising results. Although such interventions have contributed to reductions in firearm injuries, there is room for continued improvement, especially targeted toward reducing the number of unintentional firearm injuries among

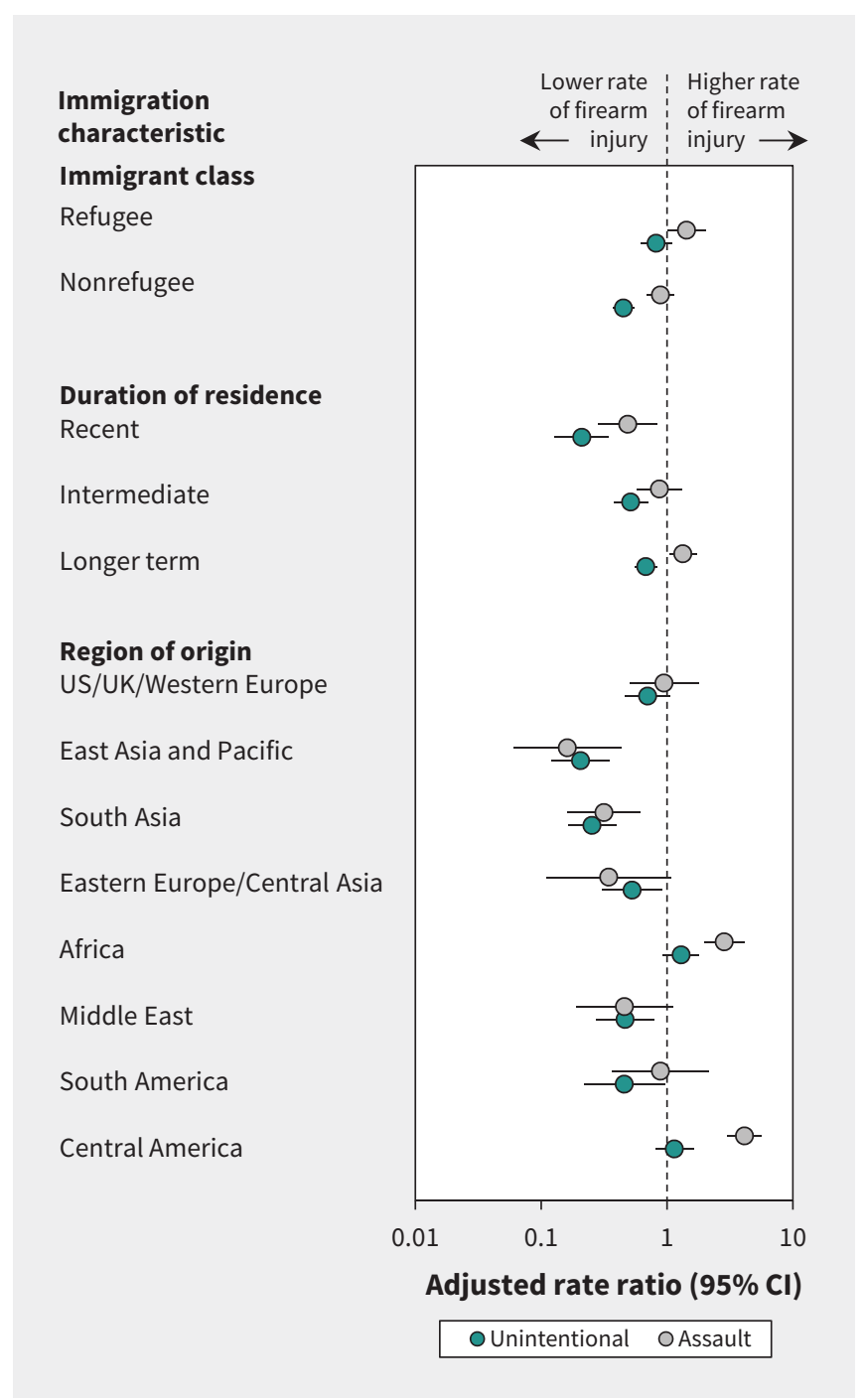

Figure 1: Adjusted rate ratios for firearm injuries (unintentional and assault-related) by immigration characteristics. Each immigration characteristic was modelled separately and adjusted for age, sex, income quintile and rurality. Values greater than 1 indicate a higher rate of firearm injury compared with the reference group (nonimmigrants). $\mathrm{Cl}=$ confidence interval. nonimmigrant children and youth and assault-related firearm injuries in subgroups of immigrant youth.

\section{Strengths and limitations}

Major strengths of this study include the large sampling frame, with almost complete provincial coverage of children and youth in Ontario, and detailed immigration data which allowed for contextualization of contributing immigration factors. We reported on all firearm injuries, including those involving children and youth presenting to the emergency department and admitted to hospital, rather than more commonly reported mortality data, which allowed better ascertainment of the burden of this public health problem.

There are some important limitations. The immigration data available to us did not include information on undocumented or temporary immigrants. Paternal immigration, parental education level or employment status, and secondary migration data were not available and may be associated with risk of firearm injury. In some instances, small numbers made more detailed risk stratification impossible.

\section{Conclusion}

We counted almost 1800 firearm injuries among children and youth in Ontario over a 5-year period, which represents almost 1 injury per day. Nonimmigrant youth had the highest rates of unintentional firearm injury. Immigrant children and youth were at lower risk of unintentional firearm injury overall, but the risk of assault-related firearm injury was higher among refugees and among immigrants from Africa and Central America compared with nonimmigrants. Understanding why the immigrant paradox was not observed in these subgroups needs further study and intervention. Prevention strategies for firearm safety should target nonimmigrant youth as well as these newly identified high-risk immigrant populations.

\section{References}

1. Leventhal JM, Gaither JR, Sege R. Hospitalizations due to firearm injuries in children and adolescents. Pediatrics 2014;133:219-25.

2. Karp A. Small Arms Survey 2007: guns and the city. Cambridge (UK): Cambridge University Press; 2007.

3. Elnour AA, Harrison J. Lethality of suicide methods. Inj Prev 2008;14:39-45.

4. Dowd MD, Sege RD; Council on Injury, Violence, and Poison Prevention Executive Committee. American Academy of Pediatrics. Firearm-related injuries affecting the pediatric population. Pediatrics 2012;130:e1416-23.

5. Firearms, accidental deaths, suicides and violent crime: an updated review of the literature with special reference to the Canadian situation. Ottawa: Department of Justice; 2015. Available: www.justice.gc.ca/eng/rp-pr/csj-sjc/jsp-sjp/ wd98_4-dt98_4/p3.html\#a34 (accessed 2016 June 29).

6. Snider $\mathrm{CE}$, Ovens $\mathrm{H}$, Drummond A, et al. CAEP position statement on gun control. CJEM 2009;11:64-72, 73-83.

7. Macpherson AK, Schull MJ. Penetrating trauma in Ontario emergency departments: a population-based study. CJEM 2007;9:16-20.

8. Erickson PG, Butters JE, Cousineau MM, et al.; Drugs, Alcohol and Violence International (DAVI) Team. Girls and weapons: an international study of the perpetration of violence. J Urban Health 2006;83:788-801.

9. Birken CS, Parkin PC, To T, et al. Neighborhood socioeconomic status and homicides among children in urban Canada. Pediatrics 2009;123:e815-9.

10. Dahlberg LL, Ikeda RM, Kresnow MJ. Guns in the home and risk of a violent death in the home: findings from a national study. Am J Epidemiol 2004;160:929-36.

11. Chapdelaine A, Maurice P. Firearms injury prevention and gun control in Canada. CMAJ 1996;155:1285-9.

12. Homicide in Canada, 2014. Ottawa: Statistics Canada; 2014. Available: www.statcan gc.ca/pub/85-002-x/2015001/article/14244-eng.htm\#a4 (accessed 2016 June 29)

13. Facts and figures 2013 - Immigration overview: permanent and temporary 
residents. Ottawa: Citizenship and Immigration Canada; 2013. Available: www.cic.gc.ca/english/resources/statistics/facts2013/index.asp (accessed 2016 July 8).

14. Saunders N, Macpherson A, Guttmann A. Predictors of unintentional injuries in pediatric immigrants in Ontario [abstract]. Canadian Paediatric Societies Annual Meeting; 2016; Charlottetown: p. 89.

15. Saunders NR, To T, Parkin PC, et al. Emergency department revisits by urban immigrant children in Canada: a population-based cohort study. J Pediatr 2016; 170:218-26

16. Vaughn MG, Salas-Wright CP, DeLisi M, et al. The immigrant paradox: immigrants are less antisocial than native-born Americans. Soc Psychiatry Psychiatr Epidemiol 2014;49:1129-37.

17. Johnson-Motoyama M. Does a paradox exist in child well-being risks among foreign-born Latinos, U.S.-born Latinos, and Whites? Findings from 50 California cities. Child Abuse Negl 2014;38:1061-72.

18. Kliewer EV. Homicide victims among Australian immigrants. Aust J Public Health 1994;18:304-9.

19. Facts and figures 2011 - Immigration overview: permanent and temporary residents. Ottawa: Citizenship and Immigration Canada; 2012.

20. TPS crime statistics. Toronto: Toronto Police Service; 2016. Available: www. torontopolice.on.ca/statistics/ytd_stats.php (accessed 2016 June 29).

21. Kralj B. Measuring rurality - RIO2008_BASIC: methodology and results. Toronto: Ontario Medical Association; 2009.

22. Dataset repository. Toronto: Institute for Clinical Evaluative Sciences; 2013. Available: https://datadictionary.ices.on.ca/Applications/DataDictionary/Default.aspx (accessed 2016 Jan. 6)

23. Chiu M, Lebenbaum M, Lam K, et al. Describing the linkages of the immigration, refugees and citizenship Canada permanent resident data and vital statistics death registry to Ontario's administrative health database. BMC Med Inform Decis Mak 2016;16:135.

24. Annest JL, Hedegaard H, Chen LH, et al. Proposed framework for presenting injury data using ICD-10-CM external cause of injury codes. Atlanta: US Centers for Disease Control and Prevention; 2014.

25. LeMier M, Cummings $P$, West TA. Accuracy of external cause of injury codes reported in Washington State hospital discharge records. Inj Prev 2001;7:334-8.

26. Holder Y, Peden M, Krug E. Injury surveillance guidelines. Geneva: World Health Organization; 2001.

27. Laursen B, Moller H. Unintentional injuries in children of Danish and foreignborn mothers. Scand J Public Health 2009;37:577-83.

28. Fowler KA, Dahlberg LL, Haileyesus T, et al. Firearm injuries in the United States. Prev Med 2015;79:5-14.

29. Firearms and violent crime in Canada, 2012. Ottawa: Statistics Canada; 2015.
Available: http://www.statcan.gc.ca/pub/85-002-x/2014001/article/11925-eng. htm (accessed 2016 July 7).

30. Ponzer S, Sundquist J, Johansson SE, et al. Gender, marital status and ethnicity. A Swedish retrospective study of criminality, morbidity and mortality among victims of non-fatal firearm injuries. Ethn Health 1998;3:275-82.

31. Indiani L, Martini A, Chellini E. Mortality for accident in Tuscany region (central Italy) in immigrants from countries at high migration rates [article in Italian]. Epidemiol Prev 2014;38:46-52.

32. Sorenson SB, Shen H. Homicide risk among immigrants in California, 1970 through 1992. Am J Public Health 1996;86:97-100.

33. Pottie K, Dahal G, Georgiades K, et al. Do first generation immigrant adolescents face higher rates of bullying, violence and suicidal behaviours than do third generation and native born? J Immigr Minor Health 2015;17:1557-66.

34. Chavez JM, Griffiths E. Neighborhood dynamics of urban violence: understanding the immigration connection. Homicide Stud 2009;13:261-73.

35. Tita GE. Strategies for reducing gun violence: the role of gangs, drugs and firearm accessibility. Ottawa: National Crime Prevention Centre, Public Safety Canada; 2007. Available: https://www.publicsafety.gc.ca/cnt/rsrcs/pblctns/ rdcng-gn-vlnc/index-en.aspx (accessed 2016 July 7).

36. Miller M, Azrael D, Hemenway D, et al. Firearm storage practices and rates of unintentional firearm deaths in the United States. Accid Anal Prev 2005;37:661-7.

37. Gushulak BD, Pottie K, Hatcher Roberts J, et al.; Canadian Collaboration for Immigrant and Refugee Health. Migration and health in Canada: health in the global village. CMAJ 2011;183:E952-8.

38. Xuan Z, Hemenway D. State gun law environment and youth gun carrying in the United States. JAMA Pediatr 2015;169:1024-31.

39. Bridges FS. Gun control law (Bill C-17), suicide, and homicide in Canada. Psychol Rep 2004;94:819-26.

40. Grossman DC, Mueller BA, Riedy C, et al. Gun storage practices and risk of youth suicide and unintentional firearm injuries. JAMA 2005;293:707-14.

41. The Breaking the Cycle Youth Gang Exit and Ambassador Leadership Program. Ottawa: Public Safety Canada; 2016. Available: https://www.publicsafety.gc. $\mathrm{ca} / \mathrm{cnt} / \mathrm{rsrcs} / \mathrm{pblctns} /$ brkng-ccl/index-en.aspx (accessed 2016 July 7).

42. Whitehill JM, Webster DW, Frattaroli S, et al. Interrupting violence: how the CeaseFire Program prevents imminent gun violence through conflict mediation. J Urban Health 2014;91:84-95.

43. Carter PM, Walton MA, Zimmerman MA, et al. Efficacy of a universal brief intervention for violence among urban emergency department youth. Acad Emerg Med 2016;23:1061-70.

44. Duncan TK, Waxman K, Romero J, et al. Operation PeaceWorks: a community program with the participation of a Level II trauma center to decrease gangrelated violence. J Trauma Acute Care Surg 2014;76:1208-13.

\section{Competing interests: None declared.}

This article has been peer reviewed.

Affiliations: Department of Pediatrics (Saunders, Guttmann), The Hospital for Sick Children and University of Toronto; Institute for Clinical Evaluative Sciences (Saunders, Lee, Macpherson, Guan, Guttmann); Faculty of Health (Macpherson), School of Kinesiology and Health Science, York University; Child Health Evaluative Sciences (Saunders, Guttmann), SickKids Research Institute, Toronto, Ont.

Contributors: Natasha Saunders, Alison Macpherson and Astrid Guttmann conceptualized and designed the study. Natasha Saunders, Hannah Lee, Alison Macpherson and Astrid Guttmann interpreted the results. Jun
Guan analyzed the data. Natasha Saunders and Hannah Lee drafted the initial manuscript. All of the authors revised the manuscript for important intellectual content, approved the final version to be published and agreed to act as guarantors of the work.

Funding: Astrid Guttmann and Alison Macpherson are funded through Applied Chairs in Child Health Services and Policy Research from the Canadian Institutes for Health Research. All data analyses were funded through Astrid Guttmann's research chair.

Disclaimers: This study was supported by the Institute for Clinical Evaluative Sciences (ICES), which is funded by an annual grant from the Ontario Ministry of Health and LongTerm Care (MOHLTC). The opinions, results and conclusions reported in this paper are those of the authors and are independent from the funding sources. No endorsement by ICES or the Ontario MOHLTC is intended or should be inferred.

Parts of this material are based on data and information compiled and provided by the Canadian Institute for Health Information (CIHI) and Immigration, Refugees and Citizenship Canada (IRCC). The analyses, conclusions, opinions and statements expressed in this paper are those of the authors and not necessarily those of $\mathrm{CIHI}$ and IRCC.

Accepted: Dec. 5, 2016

Correspondence to: Astrid Guttmann, astrid.guttmann@ices.on.ca 